\title{
Trepopnoea due to aneurysm of the descending thoracic aorta compressing the heart: an unusual occurrence
}

\author{
Iranna Hirapur, Navin Agrawal, Thagachagere Ramegowda Raghu, \\ Cholenahally Nanjappa Manjunath
}

Department of Cardiology, Sri Jayadeva Institute of

Cardiovascular Sciences and Research, Bangalore, Karnataka, India

\section{Correspondence to} Dr Navin Agrawal, drnavinagrawal@gmail.com

Accepted 5 April 2015

\section{(a) CrossMark}

To cite: Hirapur I, Agrawal N, Raghu TR, et al. BMJ Case Rep Published online: [please include Day Month Year] doi:10.1136/ bcr-2015-210425

\section{DESCRIPTION}

Trepopnoea is a symptom often described in relation to heart failure especially in cases having rightsided pleural effusion or other forms of unilateral lung disease. ${ }^{1-3}$ A 50 -year-old man with a history of development of severe breathlessness, profuse sweating, palpitations and dizziness on right decubitus position for the past 1-2 months was admitted with accelerated hypertension with acute pulmonary oedema. His blood pressure at the time of admission was $180 / 90 \mathrm{~mm} \mathrm{Hg}$, which dropped to $90 / 60 \mathrm{~mm} \mathrm{Hg}$ every time the patient turned to the right lateral position. Echocardiography showed a large descending thoracic aortic aneurysm measuring $8.1 \times 6.5 \mathrm{~cm}$ with spontaneous echo contrast and thrombus, compressing the left atrium and ventricle (figures 1-3, videos 1-2). CT scan confirmed the presence of a large descending thoracic aortic aneurysm compressing (arrow in figures)

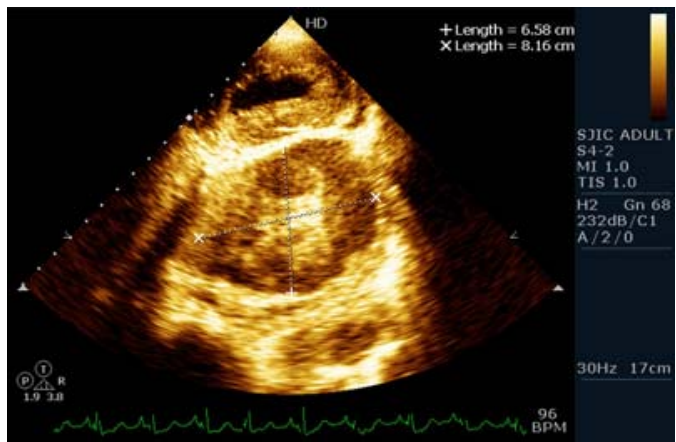

Figure 1 Modified parasternal short-axis view showing the size of aneurysm to be $6.86 \times 8.16 \mathrm{~cm}$.

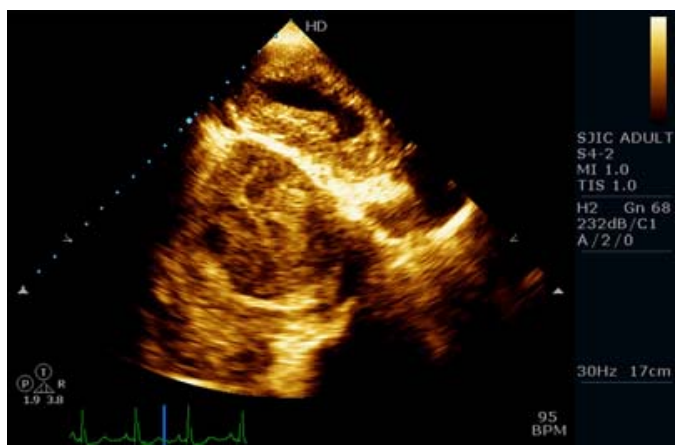

Figure 2 Parasternal long-axis view showing significant cardiac compression of the left ventricle by the grossly enlarged and aneurysmal descending aorta.

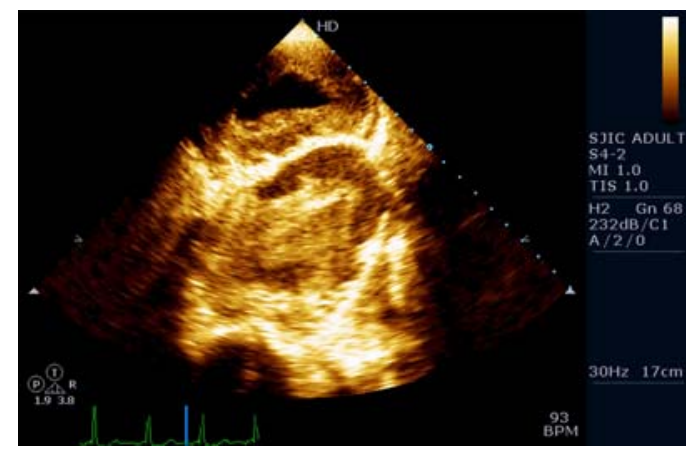

Figure 3 Modified parasternal short-axis view showing compression of the left ventricle by the large descending aortic aneurysm present immediately retrosternally.

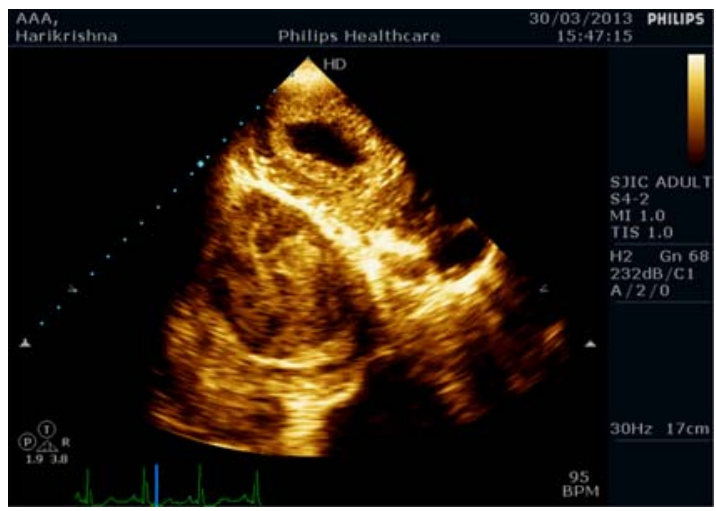

Video 1 Modified parasternal long-axis view showing significant cardiac compression of the left ventricle by the grossly enlarged and descending aneurysmal aorta.

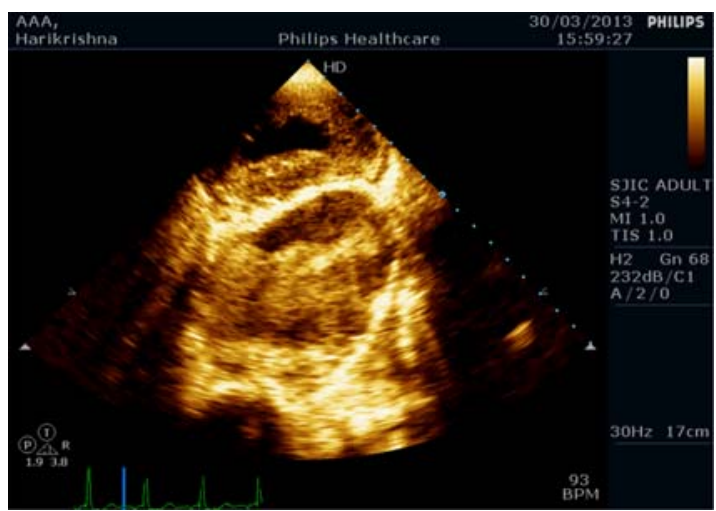

Video 2 Modified parasternal short-axis view showing compression of the left ventricle by the large descending aortic aneurysm present immediately retrosternally. 


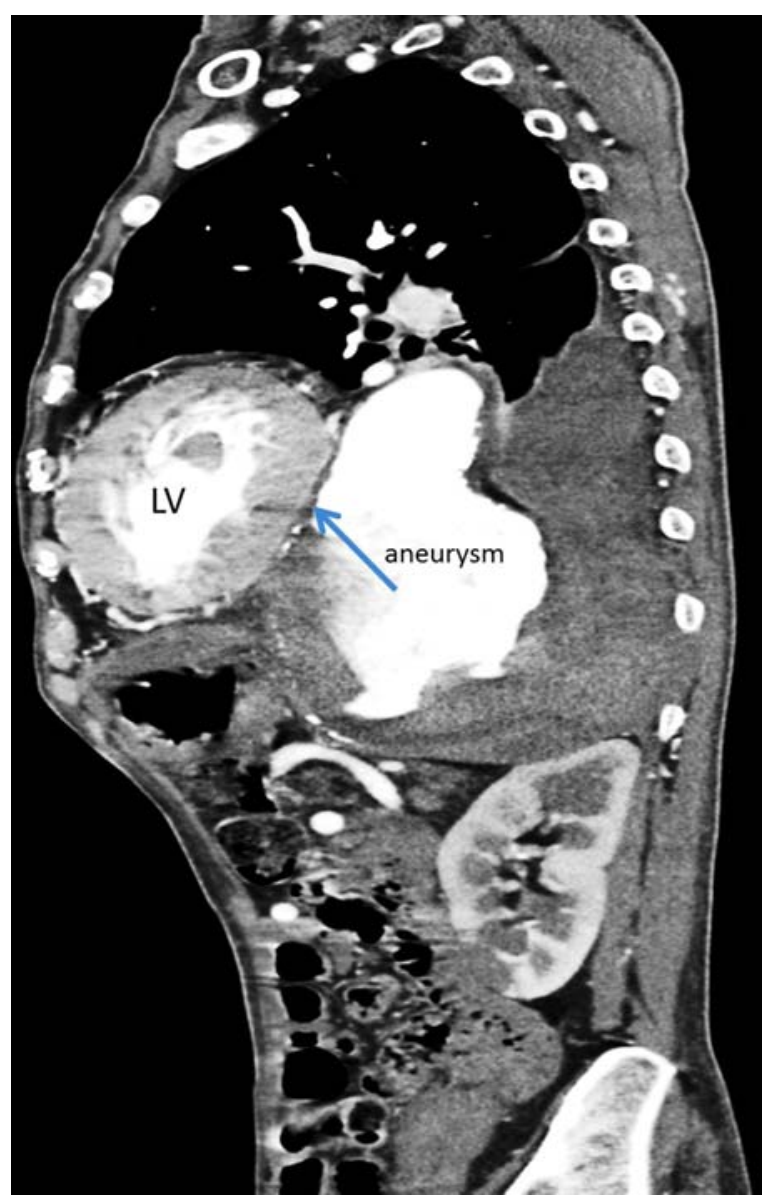

Figure 4 Sagittal section image of CT scan showing the large aneurysm compressing the left-sided cardiac chambers.

the lateral wall of left atrium and ventricle (figures 4-7). This aneurysm caused cardiac compression that worsened in the right lateral position explaining the postural variation of symptoms and hypotension. The patient underwent emergent surgical correction of the thoracoabdominal aorta because of the risk of

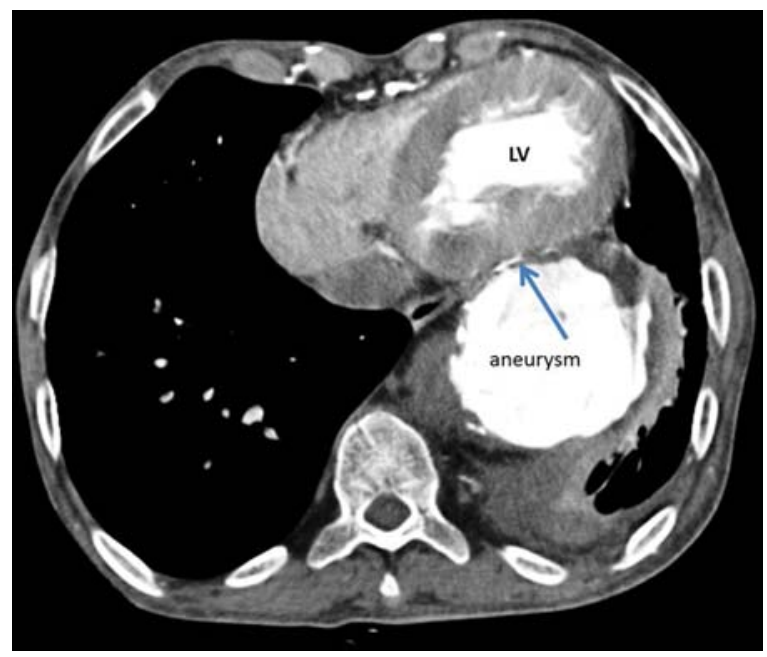

Figure 5 Transverse image of CT scan showing the large aneurysm compressing the left-sided cardiac chambers.

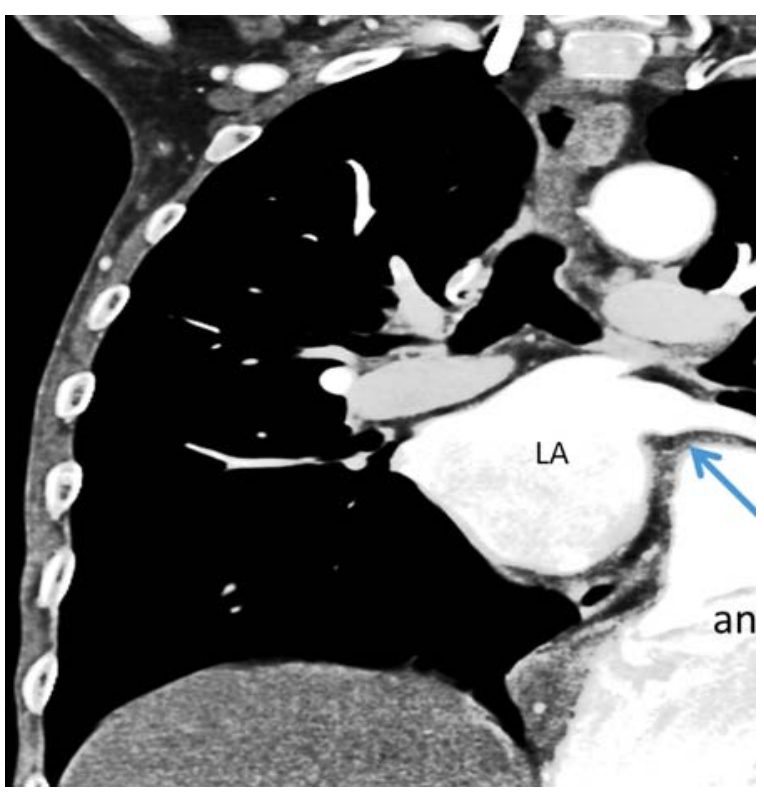

Figure 6 Anteroposterior images showing the large sized aneurysm adjacent to the heart.

impending rupture of the aneurysm; unfortunately, the patient died of disseminated intravascular coagulopathy 4 days later as a postoperative complication of surgery.

The occurrence of this symptom caused by cardiac compression by a large thoracic aneurysm has never been described and is an interesting addition to the list of possible causes, which may be helpful for cardiologists and chest physicians.

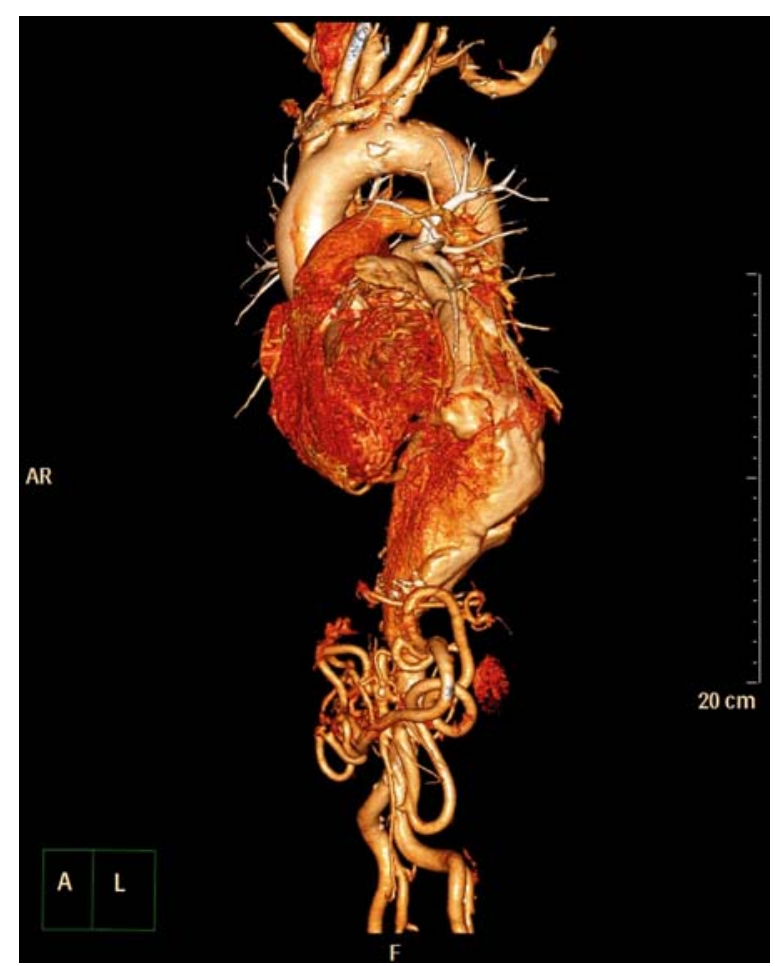

Figure 7 Three-dimensional reconstructed images showing the large sized aneurysm adjacent to the heart. 
Learning points

- Trepopnoea is an unusual symptom of an aortic aneurysm compressing the heart.

- Presence of an aneurysm should be kept as a differential diagnosis in patients presenting with trepopnoea when diagnostic tests for other common causes are negative.

- Echocardiography can be a useful screening tool for diagnosis of this rare entity, but the index of suspicion should be high to avoid missing the diagnosis.
Acknowledgements The authors would like to thank Dr Ravindran Rajendran for contributing to the concept of the manuscript and for having helped in patient care.

Competing interests None declared.

\section{Patient consent Obtained.}

Provenance and peer review Not commissioned; externally peer reviewed.

\section{REFERENCES}

1 de Araujo BS, Reichert R, Eifer DA, et al. Trepopnea may explain right-sided pleural effusion in patients with decompensated heart failure. Am J Emerg Med 2012;30:925-931.e2.

2 Gandhi NM, Greaves M, Brooks NH. Rare case of heart failure caused by compression of the left atrium by a thoracic aortic aneurysm. Heart 2004;90:e9.

3 Mehmet AC, Ibrahim K, Ercan A, et al. Aortic aneurysm compressing left atrium and causing symptoms of heart failure. Asian Cardiovasc Thorac Ann 2013;21:97-8.

Copyright 2015 BMJ Publishing Group. All rights reserved. For permission to reuse any of this content visit

http://group.bmj.com/group/rights-licensing/permissions.

BMJ Case Report Fellows may re-use this article for personal use and teaching without any further permission.

Become a Fellow of BMJ Case Reports today and you can:

- Submit as many cases as you like

- Enjoy fast sympathetic peer review and rapid publication of accepted articles

- Access all the published articles

- Re-use any of the published material for personal use and teaching without further permission

For information on Institutional Fellowships contact consortiasales@bmjgroup.com

Visit casereports.bmj.com for more articles like this and to become a Fellow 